\title{
Zgoščeni imenik zemljepisnih imen Slovenije
}

\author{
Borut Peršolja \\ Geografski inštitut Antona Melika, Znanstvenoraziskovalni center SAZU, \\ Gosposka 13, 1000 Ljubljana, Slovenija \\ e-mail: borut.persolja@zrc-sazu.si
}

\section{Izvleček}

Članek obravnava problematiko standardizacije zemljepisnih imen v Sloveniji. Izpostavljen je pomen geografskega preučevanja zemljepisnih imen, ki obsega preučevanje prisotnosti in lege zemljepisnih imen, njihovo sistematično opredeljevanje po geografskih sestavinah pokrajine in skrb za pravilno rabo in zapisovanje zemljepisnih imen v vseh medijih, ki predstavljajo pokrajino.

Ključne besede: geografija, zemljepisna imena, standardizacija, standard, Slovenija

\section{Concise Gazetteer of Slovenia}

\begin{abstract}
This article deals with the problems of standardizing geographical names in Slovenia and discusses the importance of geographically studying such names, which includes researching the presence and location of geographical names, their systematic classification according to the geographical elements of a region, and concern for the correct use and transcription of geographical names in all media presenting a region.
\end{abstract}

Key words: geography, geographical names, standardization, standard, Slovenia 


\section{UVOD}

Človek je moral zaradi boljše predstave o pokrajini, lažjega gibanja ter medsebojnega sporazumevanja, razviti učinkovit sistem razvedenja. Del tega sistema so tudi zemljepisna imena, ki so največkrat nastala $\mathrm{z}$ opredeljevanjem kraja po imenu in imena po kraju (Tuma 1925). Potrebo po poimenovanju je vodila človekova dejavnost, od naseljevanja, gospodarjenja do raziskovanja pokrajine. S poimenovanjem si je človek pokrajino predstavil in približal, postala je njegov življenjski prostor, domača pokrajina. Za večino stvari, ki so ga obdajale, je izbral imena domačin - pastir, poljedelec, ki je natančen, zelo bistroumen opazovalec narave, obdarjen s tenkim čutom za izražanje raznovrstnih oblik in pisanosti površinske odeje našega sveta (Badjura 1953). Ni si težko predstavljati, da je nekoč bilo vsako zemljepisno ime beseda z občim pomenom. Danes so zemljepisna imena del lastnoimenskega besedja, ki še vedno pomeni kar polovico posameznikovega besedišča (Bezlaj 1967).

Zemljepisna imena nastajajo stalno, veliko zemljepisnih imen, zlasti imen voda, gora in naselij, pa je zelo starih in se dolgo ohranjajo. Zaradi zelo razširjene uporabe in stalne več stoletne ali celo tisočletne prisotnosti, so zemljepisna imena postala enakovredni, sestavni del pokrajine. Zemljepisna imena pripadajo natančno določeni geografski prvini pokrajine ali geografskemu objektu v pokrajini, ki ga tako še podrobneje določajo in pojasnjujejo. V pokrajini nam olajšajo ugotavljanje stojne točke in identifikacijo posameznih geografskih objektov ter njihovo prepoznavanje $\mathrm{v}$ nizu objektov iste vrste.

Med najbolj uveljavljena sredstva za posredovanje zemljepisnih imen sodijo zemljevidi. S premišljeno oblikovanim napisom (tip pisave, velikost črk) zemljepisnega imena na zemljevidu predstavimo geografske in jezikovne lastnosti na enem mestu. Zaradi tehničnih omejitev in drugih razlogov zemljevidi ne vsebujejo vseh zemljepisnih imen, ki so v pokrajini.

Zemljepisna imena so rezultat razvoja pokrajine in razvoja jezika. $\mathrm{Ob}$ dolgotrajni rabi so nekatera zemljepisna imena izgubila svoj nekdanji stvarni pomen, predmetno in besedotvorno prepoznavnost. Če so jo ohranila, so nosilec sporočila o stanju in rabi pokrajine v času nastanka in zanesljiv spremljevalec procesa preoblikovanja pokrajine od prvobitne do današnje kulturne podobe. Tista, ki so se ohranila in so v rabi še danes, imajo zato (neformalni) status zgodovinskih in kulturnih spomenikov in so pomemben del nacionalne kulturne dediščine. 


\section{RAZISKOVANJE ZEMLJEPISNIH IMEN}

Pri raziskovanju zemljepisnih imen je naloga geografije preučevanje prisotnosti, razširjenosti in lege vseh zemljepisnih imen na celotnem ozemlju Republike Slovenije in sosedstvu, natančno in sistematično opredeljevanje zemljepisnih imen po geografskih prvinah pokrajine na katere se zemljepisna imena nanašajo in razvrščanje $\mathrm{v}$ tipe zemljepisnih imen. $\mathrm{V}$ ospredju je tudi skrb za pravilno rabo in zapisovanje zemljepisnih imen $\mathrm{v} v \mathrm{vseh}$ medijih, ki predstavljajo pokrajino (Peršolja 1998a).

Geografa največkrat zanima prvotna povezanost zemljepisnega imena s pokrajino, s tistimi njenimi značilnostmi ali sestavinami, ki so objektu ponavadi dale ime. Tipizacija zemljepisnih imen oziroma njihovo razvrščanje po geografski vsebini je primer raziskovanja, kjer zaradi časovne oddaljenosti in zabrisane vzročno-posledične zveze ob začetnem poimenovanju, izhajamo iz sedanjega poimenovanja geografskega objekta ali zapisa zemljepisnega imena nazaj h geografskim značilnostim objekta ali pokrajine (Peršolja 1998).

Seveda pa je cilj - dosledna pravilna in poenotena raba domačih in tujih zemljepisnih imen oziroma standardiziranje - moč uresničiti le z interdisciplinarnostjo, ki je hkrati pogoj in edina možnost za uspešno in kakovostno ukvarjanje z zemljepisnimi imeni. V primeru zemljepisnih imen to pomeni sodelovanje različnih strok in znanosti: jezikoslovja, zgodovine, kartografije, geodezije in geografije. Tovrstne pogoje dela v Sloveniji zagotavlja Komisija za standardizacijo zemljepisnih imen Vlade Republike Slovenije, ki deluje kot stalno delovno telo vlade. Osnovna naloga komisije je usmerjanje in usklajevanje dela ter reševanje problematike na področju standardizacije zemljepisnih imen v Republiki Sloveniji, deluje pa tudi na znanstvenem in mednarodnem področju in skrbi za promocijo stroke.

Na področju standardizacije zemljepisnih imen komisija določa merila za pisanje in rabo zemljepisnih imen $\mathrm{v}$ slovenskem jeziku in jezikih narodnih manjšin v Republiki Sloveniji, sprejema merila za pisanje in rabo slovenskih zemljepisnih imen na ozemljih zunaj Republike Slovenije, kjer živi slovenska manjšina, sodeluje z nacionalnim organom za standarde in s tehničnim odborom, pristojnim za standardizacijo zemljepisnih imen $\mathrm{v}$ nacionalnem organu za standarde s pobudami za sprejem novih standardov, izdaja imenike zemljepisnih imen in izdaja druge standardizacijske dokumente na področju zemljepisnih imen (toponimska navodila, slovar toponimske terminologije itd) (Poslovnik 2002).

Standardizacija zemljepisnih imen je strokovno opravilo, ki obsega več delovnih stopenj, ki si sledijo v zaporedju. Prva stopnja je določitev izhodišč strokovne obravnave, sledi preučitev delovne in druge standardizacijske doku- 
mentacije, zatem oblikovanje predlogov za rešitev problema, usklajevanje predlogov in sprejem usklajenega stališča o standardiziranih zemljepisnih imenih oziroma končni rezultat. Rezultat standardizacije sta imenik zemljepisnih imen in zemljevid.

\section{METODOLOGIJA PRIPRAVE IMENIKA}

\subsection{Izbor zemljepisnih imen}

Osnova za izbor zemljepisnih imen za zgoščeni imenik so bila zemljepisna imena z zemljevida, ki ga je pripravil Geodetski inštitut Slovenije in zemljepisna imena $\mathrm{z}$ zemljevida, ki ga je $\mathrm{v}$ enakem merilu za svoje potrebe izdelal Geografski inštitut Antona Melika ZRC SAZU. Ob pregledu je bilo ugotovljeno, da obstaja 77 zemljepisnih imen, ki so na zemljevidu Geodetskega inštituta in jih ni na zemljevidu Geografskega inštituta, hkrati pa tudi, da obstaja 442 zemljepisnih imen, ki so na zemljevidu Geografskega inštituta, ne pa tudi na zemljevidu Geodetskega inštituta. Čeprav gre za zemljevida majhnega merila, pa so - tako zgovorno dokazujejo podatki, razlike v vsebini lahko zelo velike.

Pred dokončnim izborom zemljepisnih imen so bili pregledani tudi največji svetovni atlasi, ki imajo območje Slovenije pokrito z zemljevidi majhnih meril. V atlasu Britannica iz leta 1989 je ozemlje Slovenije predstavljeno na dveh listih merila $1: 1.000 .000$. Na obeh listih najdemo skupaj 102 imeni: 2 imeni držav, 14 imen gorskih skupin in vrhov, eno ime jezera, 68 imen naselij, 4 imena pokrajin, 3 mejne prelaze in 10 imen rek. Večjih napak nismo opazili, med naselja se je vrinil zaselek Na Logu, ime Julijske Alpe je zapisano v angleščini, Prekmurje je Prekomurje in Grintovec Grintavec. V The Timesovem atlasu iz leta 1994 so deli ozemlja Slovenije predstavljeni na dveh listih merila $1: 1.000 .000$, celotno ozemlje pa na enem listu merila $1: 2.500 .000$. Na obeh listih merila $1: 1.000 .000$ najdemo skupaj 103 imena: 10 imen gorskih skupin in vrhov, eno ime jezera, 79 imen naselij, 2 imeni pokrajin, en mejni prelaz in 10 vodnih imen. Tudi na tem zemljevidu je Prekmurje Prekomurje in Grintovec Grintavec. V obeh atlasih se je pojavilo 39 zemljepisnih imen, ki jih ni bilo na nobenem od zemljevidov, ki sta ju pripravila Geodetski in Geografski inštitut.

Dokončni izbor je opravila delovna skupina, potrdila pa Komisija za standardizacijo zemljepisnih imen. Z uredniškim izborom smo določili točkovne, linijske in površinske pokrajinske sestavine in njim pripadajoča zemljepisna imena. Sledilo je izbiranje, poenostavljanje, poudarjanje, razvrščanje, združevanje, pretvarjanje in premikanje zemljepisnih imen, pri čemer so se ti 
postopki izvajali sočasno na zemljevidu in $\mathrm{v}$ delovni različici zgoščenega imenika zemljepisnih imen.

Čeprav bi moral biti zemljevid kot sestavni del zgoščenega imenika zemljepisnih imen pravzaprav tematski zemljevid, saj je v ospredju vsebina povezana z zemljepisnimi imeni, je obveljala odločitev, da se pripravi splošnogeografski oziroma pregledni zemljevid, ki pa vsebuje več zemljepisnih imen, kot je to običajno.

\subsection{Merila za izbor zemljepisnih imen}

Za zemljepisna imena naselij smo kot merilo izbrali številu prebivalcev v naselju leta 2000. V seznam so bila uvrščena vsa naselja z več kot 5000 prebivalci. Pri jezerih in slapovih je bilo merilo njihova velikost, njihov pomen $\mathrm{z}$ vidika naravne in kulturne dediščine in turističen pomen. Pri rekah je bilo

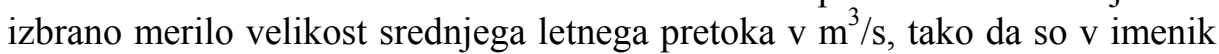
uvrščena zemljepisnih imen rek, ki imajo povprečni letni pretok večji od $3 \mathrm{~m}^{3} / \mathrm{s}$. Med izbranimi imeni gora so imena najvišjih vrhov gorskih skupin, ostala imena pa so bila izbrana glede na prazen prostor na zemljevidu. Glede na pokrajinske značilnosti Slovenije so bila dodana tudi imena jam in brezen (Postojnska jama, Čehi II ...).

Pri izboru zemljepisnih imen pokrajin je bila upoštevana regionalizacija Slovenije, ki je bila prvič objavljena v Geografskem vestniku (Kladnik 1996). Pri zemljepisnih imenih pokrajinskih sestavin na državni meji (na primer Trdinov vrh/Sveta Gera, Peč/Monte Forno/Ofen) je bilo dogovorjeno, da ohranimo samo domača imena. $\mathrm{K}$ domačim zemljepisnim imenom na območju sosednjih držav smo dodali tudi tuja (slovenska) zemljepisna imena. V pojasnilo povejmo, da se v Sloveniji šteje za domače ime slovensko ime in za tuje ime hrvaško, italijansko, avstrijsko in madžarsko ime, enako velja za zemljepisna imena na meji. Zunaj Slovenije je domače ime hrvaško, italijansko, avstrijsko in madžarsko ime in tuje slovensko ime (zapisano v oklepaju). Takšna odločitev je bila sprejeta prav zato, ker so na zemljevidu na ozemlju drugih držav vsa ostala slovenska imena zapisana v oklepajih (na primer Klagenfurt (Celovec)).

Že omenjeno interdisciplinarno raziskovanje zemljepisnih imen bi se moralo $\mathrm{v}$ zgoščenem imeniku zemljepisnih odraziti tudi tako, da bi ta obsegal celotno izrazno podobo zemljepisnih imen. Lastna imena imajo svojo izrazno podobo, to je tisto, kar vidimo, kadar je napisano, in tisto, kar slišimo, kadar se izgovarja. Zgoščeni imenik slednjega še nima, upamo pa, da bodo prihodnji imeniki vsebovali tudi te vsebine. 
Slika 1: Izsek zemljevida z zemljepisnimi imeni iz Zgoščenega imenika zemljepisnih imen Slovenije.

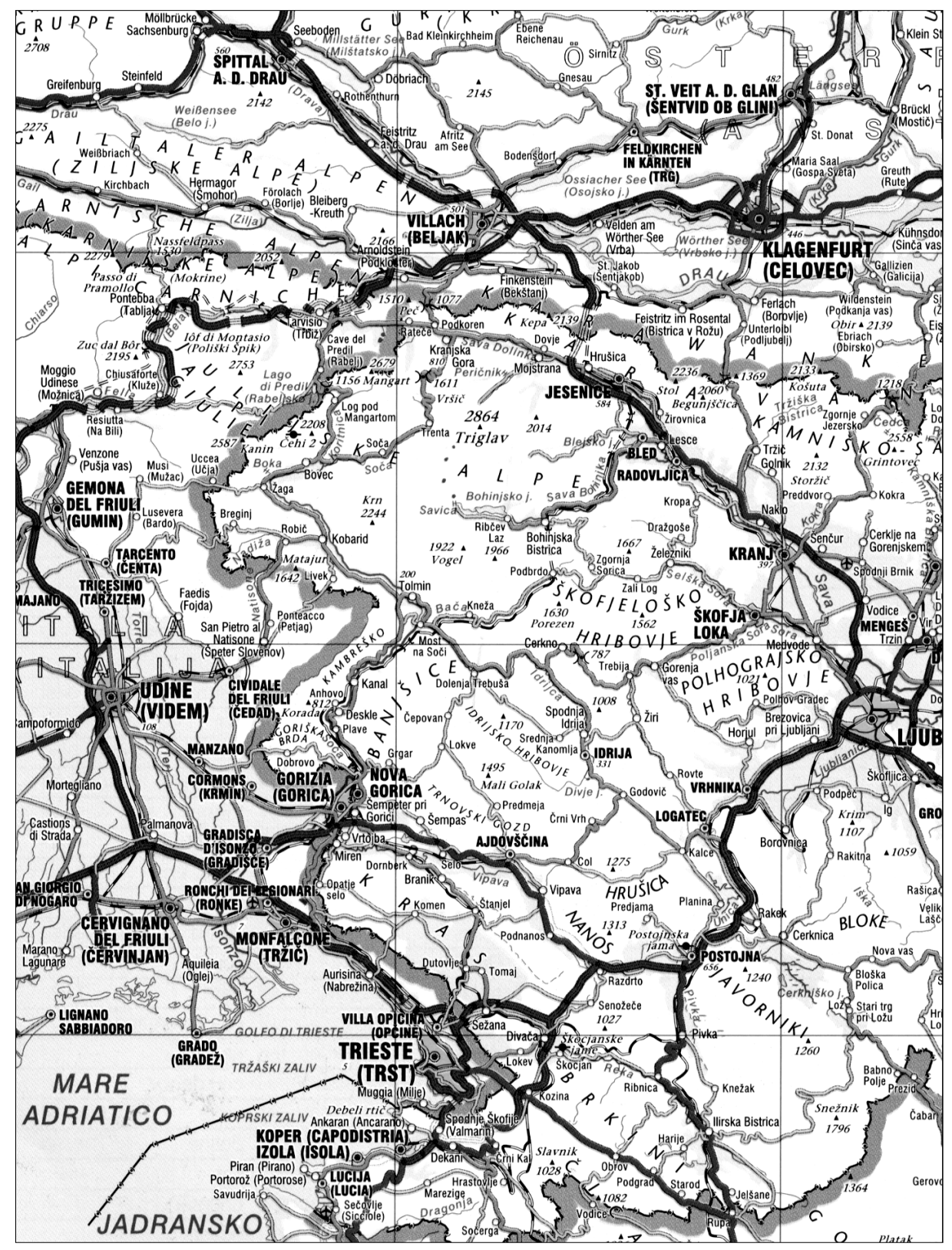

Vir: Pregledna karta Slovenije merila $1: 1.000 .000$, (C) Geodetska uprava Republike Slovenije, 2001. Dovoljenje za uporabo pregledne karte Slovenije merila 1 : 1.000.000, št. 90411-328/2002-2, 19. 11. 2002. 


\section{PREGLED ZEMLJEPISNIH IMEN}

Zemljepisna imena smo pregledovali z nekoliko prilagojeno metodologijo, kakršna je bila uporabljena pri dosedanjih pregledih (Orožen Adamič 1996, Pavšek 1996, Peršolja 1998, Hrvatin 1999, Hrvatin 1999a, Kladnik 2000, Gabrovec 2001). Pri pregledu smo ugotavljali, pravilnost zapisa v imeniku in na zemljevidu, ki obsega lego, pravopisni zapis in tipografijo napisa, pravilnost opredelitve tipa zemljepisnih imen in primernost redakcijskega izbora zemljepisnega imena za objavo. Ob primerjanju podatkov smo odpravljali nedvoumne pravopisne napake (na primer napačen prepis imena, zamenjan vrstni red črk ...) ter napake pri geografski interpretaciji oziroma določevanju tipa zemljepisnega imena. Posebno pozornost smo namenili naseljem.

Določevanje tipov zemljepisnih imen in geografskih objektov je potekalo na podlagi uredniško sprejetega kartografskega ključa, ki je opredeljeval dvanajst tipov zemljepisnih imen: brezno, jama; država; jezero; morje; naselje; pokrajina; reka; rt; sedlo; slap; vzpetina in zaliv.

Pri pravopisnem pregledu zemljepisnih imen smo upoštevali pravila slovenskega pravopisa (Slovenski pravopis 2001) oziroma rešitve, navedene $\mathrm{v}$ dokumentu Komisije za standardizacijo zemljepisnih imen Vlade Republike Slovenije z naslovom Pravopisno ustrezen zapis zemljepisnih in stvarnih lastnih imen v Registru zemljepisnih imen in Registru prostorskih enot (Furlan, Gložančev, Šivic-Dular 2001). Dodatno so bili upoštevani še naslednji viri: za avstrijska zemljepisna imena smo dobili zgoščenko z zemljepisnimi imeni (Geographische Namendatabank Österreich 2000), ki ga je posredovala avstrijska komisija za zemljepisna imena, pri slovenskih, madžarskih, italijanskih in hrvaških zemljepisnih imenih smo uporabili rešitve iz dosedanjih pregledov zemljepisnih imen na Državnih topografskih kartah v merilu $1: 25.000$ in $1: 50.000$, upoštevali pa smo tudi toponimska navodila sosednjih držav (Toniolo 1999). Pri pregledu italijanskih, hrvaških in madžarskih imen smo upoštevali tudi mnenja zunanjih sodelavcev.

Pri pregledu zemljepisnih imen so se pojavili naslednji glavni problemi:

Za isti geografski objekt ali sestavino pokrajine lahko obstaja več različic poimenovanja - na primer Korada ali Kobališče, Žumberak ali Žumberačko gorje. Pri oblikovanju končne rešitve smo podrobno pregledali in preštudirali obstoječe vire in se posvetovali z zunanjimi sodelavci.

Nedorečeno je zapisovanje občih pojmov pred zemljepisnimi imeni - na primer slap Savica ali Slap Savica ali Savica. Pri tovrstnih imenih ni jasno ali so obči pojmi sestavni oziroma generični del zemljepisnega imena, v katerih primerih obči pojem zamenja na zemljevidu dogovorjeni topografski znak in ali je v tem primeru obči pojem sploh še treba pisati pred ostalim delom zemljepisnega imena. Pri reševanju tovrstnih problemov smo se odpovedali rešit- 
vam iz prejšnjih elaboratov (Orožen Adamič 1996, Pavšek 1996, Peršolja 1998, Hrvatin 1999, Hrvatin 1999a, Kladnik 2000, Gabrovec 2001) in smo takšna zemljepisna imena pisali brez občega pojma: Savica, Rinka ...

Velikokrat je vprašljiva določitev obsega pokrajinske sestavine, ki jo označuje zemljepisno ime, za nekatere pokrajinske sestavine pa je težavno enolično opredeljevanje tipov zemljepisnih imen (Haloze ali Pohorje lahko opredelimo kot gričevje oziroma hribovje - gorsko ime ali kot pokrajino).

Nemalokrat smo v dvomih tudi glede pravilnega pravopisnega zapisa. $\mathrm{Ob}$ obravnavi predloga standardizacijskega dokumenta je Komisija za standardizacijo zemljepisnih imen obravnavala vprašanje pravilnega zapisa imen vodotokov Kamniške Bistrice in Tržiške Bistrice. Problem nastane, ker v primeru Bistrice ni jasno, ali gre za obče ali lastno ime. Člani komisije so soglašali, da pri tokratnem imeniku in zemljevidu uporabimo ustaljeno obliko zapisa Kamniške Bistrice z veliko začetnico, uredniškemu odboru Pravopisne komisije pa zastavijo vprašanje o (ne)pravilnosti takega zapisa. Od sprejetih rešitev omenimo še to, da smo dvojno ime Hrib - Loški potok, ki je sestavljeno iz naselbinskega in nenaselbinskega imena zapisali z nestičnim vezajem. Neprvi del (potok) drugega dela dvojnega imena - Loški potok, ki je pokrajinsko in ne naselbinsko ime, pa smo zapisali z malo začetnico.

Nekatera zemljepisna imena so na zemljevidu zaradi različnih tehničnih omejitev krajšana ali deljena $v$ dve vrsti. S premišljenim izborom tipa in velikosti črk ter postavitvijo napisov smo se tej težavi $\mathrm{v}$ največji meri zavestno izognili.

\section{REZULTATI}

Rezultat standardizacije sta zgoščeni imenik zemljepisnih imen Slovenije in zemljevid. Zgoščeni imenik zemljepisnih imen Slovenije vsebuje 842 zemljepisnih imen na zemljevidu Republike Slovenije v merilu $1: 1.000 .000$. Obsega 463 standardiziranih zemljepisnih imen na območju Slovenije in nestandardizirana zemljepisna imena izven Slovenije: 53 na območju Italije, 127 na območju Avstrije, 16 na območju Madžarske in 183 na območju Hrvaške. Imenik obsega tudi 138 kazalk (Ankaran/Ancarano $\rightarrow$ Ankaran), tako da zgoščeni imenik obsega skupaj 980 zemljepisnih imen. Poleg pravopisno pravilnega zapisa zemljepisnega imena sta za vsako zemljepisno ime v seznamu dodana lega v Gauß-Krügerjevi projekciji in tip zemljepisnega imena. Podatki o standardizaciji zemljepisnih imen so vnešeni tudi v Register zemljepisnih imen, ki ga vodi Geodetska uprava Republike Slovenije. 
Tabela 1: Pregled posameznih tipov zemljepisnih imen po posameznih državah.

\begin{tabular}{|l|c|c|c|c|c|c|}
\hline & Slovenija & Italija & Avstrija & Madžarska & Hrvaška & skupaj \\
\hline brezno, jama & 3 & 0 & 0 & 0 & 0 & 3 \\
\hline država & 0 & 1 & 1 & 1 & 1 & 4 \\
\hline jezero & 7 & 1 & 5 & 0 & 3 & 16 \\
\hline morje & 1 & 1 & 0 & 0 & 1 & 3 \\
\hline naselje & 336 & 39 & 98 & 13 & 152 & 638 \\
\hline pokrajina & 33 & 2 & 7 & 0 & 9 & 51 \\
\hline reka & 40 & 5 & 7 & 2 & 10 & 64 \\
\hline rt & 1 & 0 & 0 & 0 & 0 & 1 \\
\hline sedlo & 1 & 1 & 1 & 0 & 0 & 3 \\
\hline slap & 5 & 0 & 0 & 0 & 0 & 5 \\
\hline vzpetina & 35 & 2 & 8 & 0 & 6 & 51 \\
\hline zaliv & 1 & 1 & 0 & 0 & 1 & 3 \\
\hline skupaj & 463 & 53 & 127 & 16 & 183 & 842 \\
\hline kazalka $(\rightarrow)$ & 24 & 42 & 59 & 4 & 9 & 138 \\
\hline skupaj & 487 & 95 & 186 & 20 & 192 & 980 \\
\hline
\end{tabular}

Vsa imena so prikazana tudi na Pregledni karti Slovenije merila $1: 1.000 .000$. Obremenjenost zemljevida zaradi večjega števila zemljepisnih imen še vedno ni velika, saj znaša 0,55 zemljepisnega imena na $\mathrm{cm}^{2}$ površine zemljevida. To zlasti velja, če upoštevamo dejstvo, da gre za tematski zemljevid oziroma prikaz zemljepisnih imen in da je tej vsebini podrejena ostala vsebina zemljevida.

Zgoščeni imenik zemljepisnih imen Slovenije temelji na resolucijah sedmih konferenc Združenih narodov za standardizacijo zemljepisnih imen (Perko 2001). Pripravljen je bil v sodelovanju različnih strokovnjakov, kar mu daje posebno težo. Dokument bo nedvomno pripomogel k pravilnejši in doslednejši rabi zemljepisnih imen v vseh medijih, ki predstavljajo pokrajino. Vsekakor gre tudi za pomemben prispevek $\mathrm{k}$ razpoznavnosti Slovenije in slovenske kulture, saj je bil dokument, ki je izšel v knjižni obliki s slovenskim in angleškim besedilom, predstavljen na zasedanju 8 . konference Združenih narodov za standardizacijo zemljepisnih imen leta 2002 v Berlinu. Dokument je v knjižni obliki dostopen na Geodetski upravi Republike Slovenije, objavljen pa je tudi na spletni strani Komisije za standardizacijo zemljepisnih imen (http://www. sigov.si/kszi/index1.html). 


\section{Viri in literatura:}

Badjura, R., 1953. Terensko izrazoslovje. Ljudska geografija. Ljubljana, Državna založba Slovenije.

Bezlaj, F., 1967. Eseji o slovenskem jeziku. Ljubljana.

Britannica Atlas, 1989. Chicago, Encyclopedia Britannica, Inc.

Evidenca zemljepisnih imen, 1996. Konceptualni, logični in fizični model z Navodilom za vzpostavitev, verzija 2.0. Ljubljana, Geodetska uprava Republike Slovenije, Ministrstvo za okolje in prostor.

Furlan, M., Gložančev, A., Šivic-Dular, A. 2001. Pravopisno ustrezen zapis zemljepisnih in stvarnih lastnih imen. Ljubljana, Geodetska uprava Republike Slovenije.

Gabrovec, M., Hrvatin, M., Kladnik, D., Komac, B., Pavšek, M., Peršolja, B., Repolusk, P., Zorn, M., 2001. Pregled zemljepisnih imen, zajetih z Državne topografske karte v merilu $1: 25.000$ (V. del). Ljubljana, Geografski inštitut Antona Melika ZRC SAZU.

Geographische Namendatabank Österreich (Database of Austrian Geographical Names), January 1, 2000. CD-ROM. Working Group for Cartographic Toponomastics of the Austrian Cartographic Commission and the Austrian Academy of Sciences.

Hrvatin, M., Peršolja, B., Petek, F. 1999. Imenik standardiziranih imen hidronimov. Ljubljana, Geografski inštitut Antona Melika ZRC SAZU.

Hrvatin, M., Peršolja, B., Petek, F. 1999a. Priprava imenika zemljepisnih imen: Pregled hidronimov z Državne topografske karte v merilu $1: 25.000$. Ljubljana, Geografski inštitut Antona Melika ZRC SAZU.

Kladnik, D., 1996. Naravnogeografske členitve Slovenije. V: Geografski vestnik, Ljubljana.

Kladnik, D., Pavšek, M., Peršolja, B., Repolusk, P. 2000. Pregled zemljepisnih imen, zajetih z Državne topografske karte v merilu $1: 25.000$ (IV. del). Ljubljana, Geografski inštitut Antona Melika ZRC SAZU.

Medmrežje: http://www.sigov.si/kszi/index1.html (25. 10. 2002).

Perko, D., 2001. Zgoščeni imenik zemljepisnih imen Slovenije. Ljubljana, Komisija za standardizacijo zemljepisnih imen Vlade R Slovenije.

Peršolja, B., 1998. Geographical problems of onomastics in the selected example of the Kamniške-Savinjske Alps/Geografski problemi imenoslovja na izbranem primeru Kamniško-Savinjskih Alp. V: Geografski zbornik/Acta geographica, Ljubljana, str. 159-197, Geografski inštitut Antona Melika ZRC SAZU.

Peršolja, B. 1998a. Pregled zemljepisnih imen, zajetih z Državne topografske karte v merilu $1: 25.000$ (III. del). Ljubljana, Geografski inštitut Antona Melika ZRC SAZU. 
Poslovnik Komisije za standardizacijo zemljepisnih imen.

Medmrežje: http:// www.sigov.si/kszi/index1.html (25. 10. 2002).

Slovenski pravopis. Ljubljana, 2001.

The Times Atlas of the World, 1994. London, Times Books.

Toniolo, S., 1999. National standardization toponymic guidelines for map and other editors. Italy, Instituto Geografico Militare.

Tuma, H., 1925. Toponomastika. V: Geografski vestnik, Ljubljana.

\section{CONCISE GAZETTEER OF SLOVENIA}

\section{Summary}

Within the framework of the regular work and tasks of the Commission for the Standardization of Geographical Names of the Government of the Republic of Slovenia, the preparation of standardized forms of geographical names has been in progress for several years. The standardization of geographical name is a professional task that includes researching working and other standardization documentation, developing proposals for resolving problems, harmonizing proposals, and adopting a common position regarding the standardization of geographical names. The results of standardization are a register of geographical names and a map.

The Concise Gazetteer of Slovenia was published in 2001 and contains 842 geographical names on a 1:1,000,000-scale map of the Republic of Slovenia. The Concise Gazetteer of Slovenia includes 463 standardized geographical names in the territory of Slovenia as well as unstandardized geographical names outside of Slovenia: 53 in Italy, 127 in Austria, 16 in Hungary, and 183 in Croatia. Along with the orthographically correct transcription of the geographical names, the position of every geographical name in the register in a Gauß-Krüger projection and the type of geographical name have been added. All the names also appear on the map, which allows us to show standardized and unstandardized geographical names together with their geographical and linguistic characteristics in one place. 